\begin{tabular}{|c|l|}
\hline Title & The Electrical Properties of Saline Ice \\
\hline Author(s) & A ddison, J.R.; Pounder, E.R. \\
\hline Citation & Physics of Snow and Ice : proceedings, 1(1), 649-660 \\
\hline Issue Date & 1967 \\
\hline Doc URL & http://hdl.handle.net/2115/20331 \\
\hline Type & bulletin (article) \\
\hline Note & $\begin{array}{l}\text { International Conference on Low Temperature Science. I. Conference on Physics of Snow and Ice, II. Conference on } \\
\text { Cryobiology. (A ugust, 14-19, 1966, Sapporo, Japan) }\end{array}$ \\
\hline File Information & 1_p649-660.pdf \\
\hline
\end{tabular}

Instructions for use 


\title{
The Electrical Properties of Saline Ice
}

\author{
J. R. Addison* and E. R. Pounder \\ Ice Research Project, Department of Physics, McGill University, Montreal, Quebec, Canada
}

\begin{abstract}
Results of a current study of the (normalized) dielectric coefficient $\left(\varepsilon^{\prime}\right)$ and the equivalent parallel resistivity $(\rho)$ of unidirectionally frozen saline ice are given. Frequencies ranged from $20 \mathrm{~Hz}$ to 100 $\mathrm{MHz}$. Salinities were of the order 7 20 p.p.t. A detailed study of frequency dependence was carried out at $-22^{\circ} \mathrm{C}$. Values of $\varepsilon^{\prime}$ of order $10^{6}$ were observed at low frequencies, falling as (frequency) ${ }^{-1}$ to order $10^{3}$ at $10 \mathrm{kHz}$. Thereafter $\varepsilon^{\prime}$ dropped less rapidly to about 10 at $50 \mathrm{MHz}$. Results from similar samples could vary by a factor of 2 or 3 , but the same pattern of behaviour was observed. Resistivities ranged from 10 to 1000 ohm-meters, decreasing slowly with increase in frequency. The effect of variation of temperature was also studied.

A cell, with metallized nylon mesh electrodes, which become incorporated into the ice as it grows, is described, along with experimental justification for its use.
\end{abstract}

\section{Introduction}

Results of a continuing investigation of the dynamic dielectric and loss properties of artificial "sea" ice are presented. Prepared brine (Lyman and Fleming's formula; Sverdrup, 1942) was frozen unidirectionally downwards in an environment maintained at $-22^{\circ} \mathrm{C}$, producing samples having salinities from 7 to 20 p.p.t. (parts per thousand). Firstly, a detailed study was made of the frequency dependence $(20 \mathrm{~Hz}$ to $100 \mathrm{MHz})$ at the fixed temperature of $-22^{\circ} \mathrm{C}$. Then the effect of temperature (upon samples formed at $-22^{\circ} \mathrm{C}$ ) was investigated between -15 and $-35^{\circ} \mathrm{C}$. All measurements were made in a vertical direction, with respect to the surface.

Saline ice is more complicated than pure ice. It is comprised of crystalline zones (or "grains") formed from platelets of pure ice (with parallel orientations) separated by ordered rows of brine-filled pockets or cells. Each zone shows a unique $c$-axis perpendicular to the platelets. The ice lattice, as it forms, rejects the salts, which remain in the liquid brine entrapped within these cells. The pockets are often roughly cylindrical in shape, being about $0.05 \mathrm{~mm}$ in diameter and perhaps up to some $3 \mathrm{~cm}$ in length. The rows of parallel cells are separated by about $0.5 \mathrm{~mm}$ (Pounder, 1965, for example). Brine is also located between the grains. The physical properties of a single zone are usually anisotropic when directions parallel to, and perpendicular to, the brine-pocket axes are considered. The presence of brine plays an important, and often definitive, role in establishing the behaviour of the substance. Dependence of brine volume upon temperature (and salinity) (Assur, 1958) is one of the principal contributing factors to the temperature variation of any physical property.

* Jointly at Sir George Williams Unịversity, Montreal, Quebec, Canada, 
Natural sea ice is built up from these grains. Just below the surface they are small (dimensions of order $1 \mathrm{~cm}$ ) and chaotically oriented. Some $2 \sim 20 \mathrm{~cm}$ beneath the surface there is a transition region below which the grains tend strongly towards horizontal orientation of the $c$-axes. Here they are vertically elongated, 1 to $2 \mathrm{~cm}$ in diameter and up to many centimeters in height (Pounder, 1965, Chapter 2; Pounder and Little, 1959; Langleben, 1959). For new ice, salinities may run to over 20 p.p.t., while 5 p.p.t. or less is typical of annual, or older ice.

Studies in this laboratory (Perey and Pounder, 1958; Smith and Pounder, 1960) indicate that ice artificially frozen (vertically) shows this same sort of structure "in microcosm". The transition layer lies about $1 \mathrm{~cm}$ down and the grains below it are smaller, about $1 \mathrm{~cm}$ in diameter and, at most, 7 to $8 \mathrm{~cm}$ in vertical extent. (The present study involved ice from this region.)

In the interest of reproducibility, artificial ice was selected for study since its thermal history could be controlled, and its handling minimized. It is felt that the results, in spite of the structural differences, should provide a good indication of the behaviour of highly saline natural ice.

\section{Background}

Wentworth and Cohn (1964) investigated the electrical properties of natural samples between $100 \mathrm{kHz}$ to $30 \mathrm{MHz}$ (in both horizontal and vertical directions), from low salinities up to 20 p.p.t., and at temperatures down to $-40^{\circ} \mathrm{C}$. Cook (1960) measured artificial ice at $100 \mathrm{MHz}$ only, obtaining (normalized) dielectric coefficients comparable with those of pure ice at this frequency. (Dorsey, 1940; Mantis, 1951). Dichtel and Lundquist (1951) made DC resistivity measurements in both horizontal and vertical directions on natural sea ice obtaining generally higher values for the former than for the latter. DC measurements were also performed by Pounder and Little (1959). Literature searches by Cook (1960), Horigan (1953) and this laboratory have yielded few other direct referencês. Anderson (1960) has considered the electrical conductivity theoretically.

The dielectric and loss properties of pure ice have been extensively reported. Polycrystalline samples were studied by Smyth and Hitchcock (1932) (including dilute KCl solutions), Lamb (1946), Eder (1947) [whose data are reproduced in Wentworth and Cohn (1964) ], and Cummings (1952) (microwave measurements) as well as by Auty and Cole (1952), who showed that the dielectric coefficient obeys a Debye dispersion (Fröhlich, 1958). A thorough study of pure ice single crystals was made by Humbel, Jona and Scherrer (1953). Theoretical treatments have been presented by Jaccard (1959) and, recently, by Dougherty (1965). Gränicher (1963) has published a review article. Also of interest are experiments involving crystals doped with fluorides $\left(\mathrm{F}^{-}\right.$is one of the few ions accepted, apparently substitutionally, into the ice lattice) and $\mathrm{NH}_{3}$ reported by Granicher et al. (1957), Steinemann (1957) and Gränicher (1963).

\section{Experimental}

The measurement cell. As a result of its inhomogeneous, multiplephase structure, saline ice presents unique problems. "Ice capacitor" methods involving metal electrodes 
frozen on to accurately cut, thin samples (often with guard rings) as used by the investigators of pure ice, were deemed unsuitable. The sample had to be large enough to incorporate portions of several grains to obtain a result in any way indicative of the bulk properties of the material. This suggested a sample 7 or $8 \mathrm{~cm}$ in diameter and at least $1 \mathrm{~cm}$ thick.

Initially, slabs of ice were cut and soft gold-foil electrodes affixed in various ways. Measurements obtained depended strongly on the method of working the ice, the resulting degree of finish of the various surfaces, and the electrode pressure. Presumably these difficulties resulted from brine released over the surfaces during cutting. In addition, samples altered rapidly as brine bled from them. Because no reproducible results could be obtained, this method was abandoned. (Wentworth and Cohn (1964) apparently did achieve success with this technique.)

Instead, an unorthodox cell was constructed from 3 inch diameter lucite tubing (Fig. 1) having 8 goldmetallized fine nylon meshes (actually "bridal veil", with $3 \mathrm{~mm}$ openings) tightly stretched across diametral planes at uniform separations of about $2 \mathrm{~cm}(3 / 4 \mathrm{inch})$. The cell, $60 \mathrm{~cm}$ in height, was then mounted vertically in a large freezing vessel with the top mesh a few centimeters below the brine surface. During freezing, ice grew slowly downwards incorporating the cell. Examination of sections showed no alteration to the normal crystal structure, the meshes being incorporated into the grains without causing perturbation. (Wire mesh was unsuitable.) An external copper

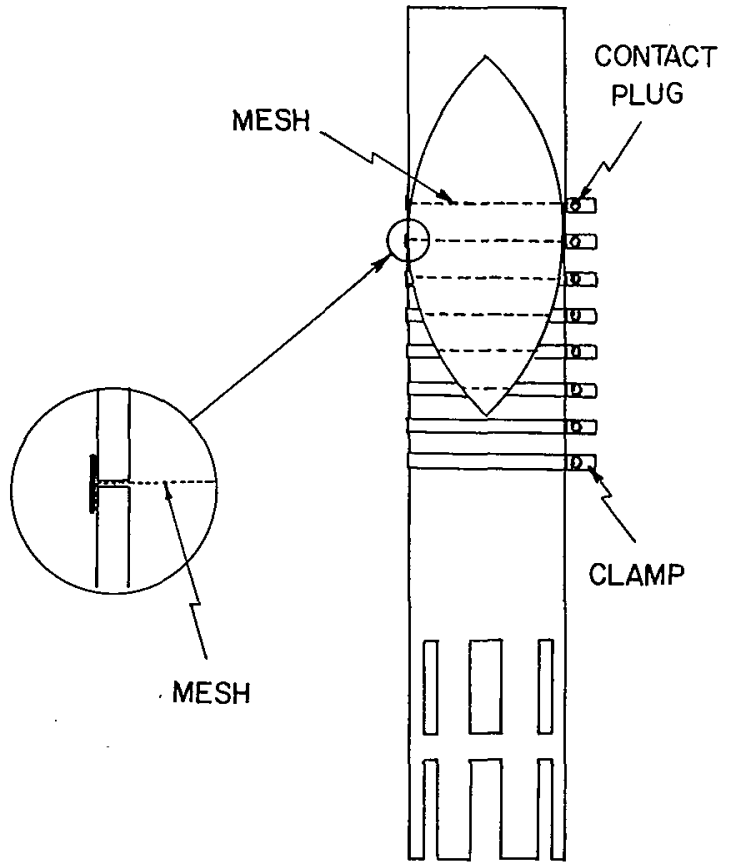

Fig. 1. Mesh cell clamp contacted the entire circumference of each mesh to facilitate connection. (Guard rings could not be used.)

After an 8 week freezing period the cell and contents were freed from the mass, externally cleaned and suspended vertically with a chosen pair of electrodes in direct contact with a coaxial line.

The advantages inherent in a sample of this form may be seen. The dimensions of the ice under study were accurately known and controlled without the necessity of shaping the substance in any way. The cell could be handled, transported or stored without the necessity of ever touching the ice itself. There were several electrodes, and pairs of these could be used to study different portions of the same mass of ice, the regions being later considered separately in the light of their individual crystal structures and salinities. Furthermore since the samples were part of a larger mass, brine content 
could change only very slowly and stability over long periods of time was obtained.

It would perhaps seem, however, that this procedure departs from sound electrical practice, since large contact resistance effects might be expected. Surprisingly little difficulty was encountered. Presumably capacitative coupling of power into the relatively conductive material in the immediate vicinity (on both sides) of a mesh helped to overcome any intrinsic contact effects.

For purposes of calculation, the mesh electrode was naively treated as if it were solid metal. Considering the wide variation of structure between various samples, internal checks on the data suggest that this assumption is probably as good as any other. The authors have become convinced, at first rather unwillingly, of the validity of the measurements obtained with this type of cell.

The ice was formed from 30 liters of artificial brine ( 35 p.p.t. salinity) in a deep cylindrical vessel, well insulated along the sides and bottom. The mass produced has been shown to contain a volume about $8 \mathrm{~cm}$ in diameter and $20 \mathrm{~cm}$ long, in the upper central region wherein the ice has characteristic structure described previously. Air bladders were included to relieve pressure. All freezing and handling was carried out in a cold room controlled to $-22 \pm 0.5^{\circ} \mathrm{C}$.

Electrical apparatus. The investigation was performed using four different General Radio bridges: type $1603(\mathrm{ZY})$ from $20 \mathrm{~Hz}$ to $20 \mathrm{kHz}$; type $916-\mathrm{AL}$ from $40 \mathrm{kHz}$ to $3 \mathrm{MHz}$; type 1606-A (400 kHz to $60 \mathrm{MHz}$ ) and type 1602-B (Admittance Meter) from $40 \sim 100 \mathrm{MHz}$. Null detection was effected by filtered amplifier below $50 \mathrm{kHz}$, and heterodyne detection was used at higher frequencies. G.R. 874 coaxial $(50 \mathrm{ohm})$ lines, connectors and hardware were employed throughout. The $50 \mathrm{ohm}$ characteristic impedance was carried right up to the sample clamps.

An especially sealed, rigid, coaxial air line connected the sample and bridges without the use of flexible lines. It had an electrical length of $1.8 \mathrm{~m}$ and a low frequency effective capacitance of $132 \mathrm{pF}$. An intensive study of its parameters revealed significant departures from "losslessness" and nominal $Z_{0}$ and therefore, these experimental parameters were empirically programmed into an electronic computer and data reduced using the full complex transmissionline equation with no approximations.

Measurements. The first samples were measured only at $-22^{\circ} \mathrm{C}$. To check for selfconsistency, groups of 2 or 3 adjacent samples were measured in series. Investigations upon a single cell often continued for up to a month.

Later samples were measured (and formed) at $-22^{\circ} \mathrm{C}$ and then cooled to $-35^{\circ} \mathrm{C}$. Curves were taken at about 2 degree intervals up to $-15^{\circ} \mathrm{C}$, and finally again at $-22^{\circ} \mathrm{C}$.

All cells were sectioned for visual examination and salinity determination by the Mohr titration. The results offered represent some 20 individual samples.

In addition a small amount of work was eventually carried out using thin sections of ice sandwiched between gold foils in order to see whether the results would be comparable with those yielded by the mesh cells. Slices of ice were obtained by mounting an additional length of 3 inch lucite tubing along-side the regular cell during freezing. After removal, this ice-filled tube could be sectioned with a bandsaw, and the sections faced on a lathe, without ever handling the ice itself. As before, the brine drained away rapidly, but a few points could be obtained before the deterioration was significant. 
Criticism of results. Readings were reproducible, over many days, of ten to better than $5 \%$. The application of 5 times the normal voltage to the bridge had no observed effect on the readings nor did application of normal bridge power continuously for 36 hours. Measurements upon the "ice-capacitor" samples were very similar to those from the mesh cells.

Significantly, when average dielectric coefficients and resistivities for 2 or 3 samples in series were computed from their individual measured values according to several different hypothetical models (which ascribed varying degrees of importance to contact resistances, blocking electrode effects, etc.) only the simplest possible model, that of 2 or 3 lossy capacitors in series, gave values very close to the experimental ones. This lends substance to the previous observation that the contact effects at the mesh do not present as great an uncertainty as might at first be expected.

The lack of guard rings and adequate shielding is evident at frequencies above $50 \mathrm{MHz}$ by greatly increased scatter. Also there is probably a self-resonance in the cell a little above $100 \mathrm{MHz}$. Hence points lying above $50 \mathrm{MHz}$ become more and more uncertain.

\section{Results}

The sample is considered equivalent to a conductance, $G(\omega)$ and a capacitance, $C(\omega)$, in parallel. If a pair of meshes is considered as a simple parallel plate capacitor, then the measured admittance, in terms of the normalized dielectric constant

$$
\varepsilon=\varepsilon^{\prime}-j \varepsilon^{\prime \prime},
$$

may be written

$$
Y=G+j \omega C=j \omega \varepsilon_{0} \varepsilon \frac{A}{l} .
$$

Where $\varepsilon_{0}=8.85 \times 10^{-12} \mathrm{MKS}, A$ and $l$ are the cross-section area and inter-electrode separation respectively, $\varepsilon^{\prime}$ is the dielectric coefficient (often denoted by $k^{\prime}$ or $k_{\mathrm{e}}$ ) and $\varepsilon^{\prime \prime}$ is related to the losses.

The conductivity is thus

$$
\sigma=\omega \varepsilon_{0} \varepsilon^{\prime \prime} .
$$

Here, following previous practice, the parallel resistivity, $\rho=1 / \sigma$ will be given.

The loss tangent and loss angle are defined by

$$
\tan \delta=\frac{\varepsilon^{\prime \prime}}{\varepsilon^{\prime}} .
$$

The frequency dispersion of $\varepsilon^{\prime}$ at $-22^{\circ} \mathrm{C}$ was similar for all samples, curves being displaced up or down from one another. Figure 2 shows two typical examples. The only significant feature is the slight downward concavity between 10 and $100 \mathrm{kHz}$. This is fairly well defined for some samples and is present to some degree for most others. High $\left(10^{5} \sim 10^{6}\right)$ low-frequency values of $\varepsilon^{\prime}$ are found, falling with increasing frequency very closely as $1 / \omega$ up to about $1 \mathrm{MHz}$ where the curves flatten somewhat. All curves lie in the range 3 to 7 at $100 \mathrm{MHz}$ (values somewhat higher than suggested by Cook (1960)). About $50 \%$ of the samples showed a rapid drop above $50 \mathrm{MHz}$. Resistivities at $-22^{\circ} \mathrm{C}$ decreased slowly with frequency. Higher values of $\varepsilon^{\prime}$ tended to occur with lower 

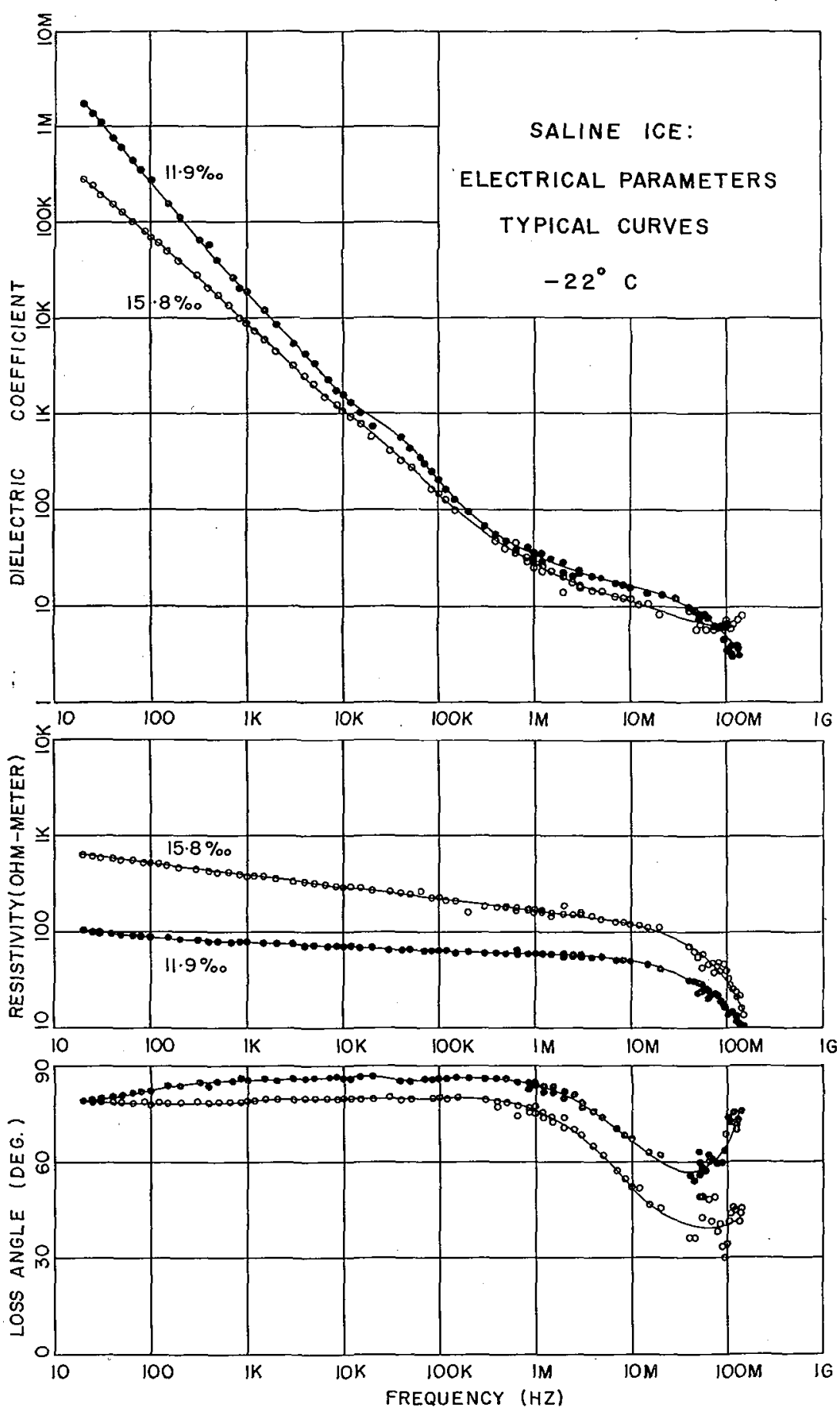

Fig. 2, Electrical paramẹtẹs, typical cưrves fọ șaline ice 


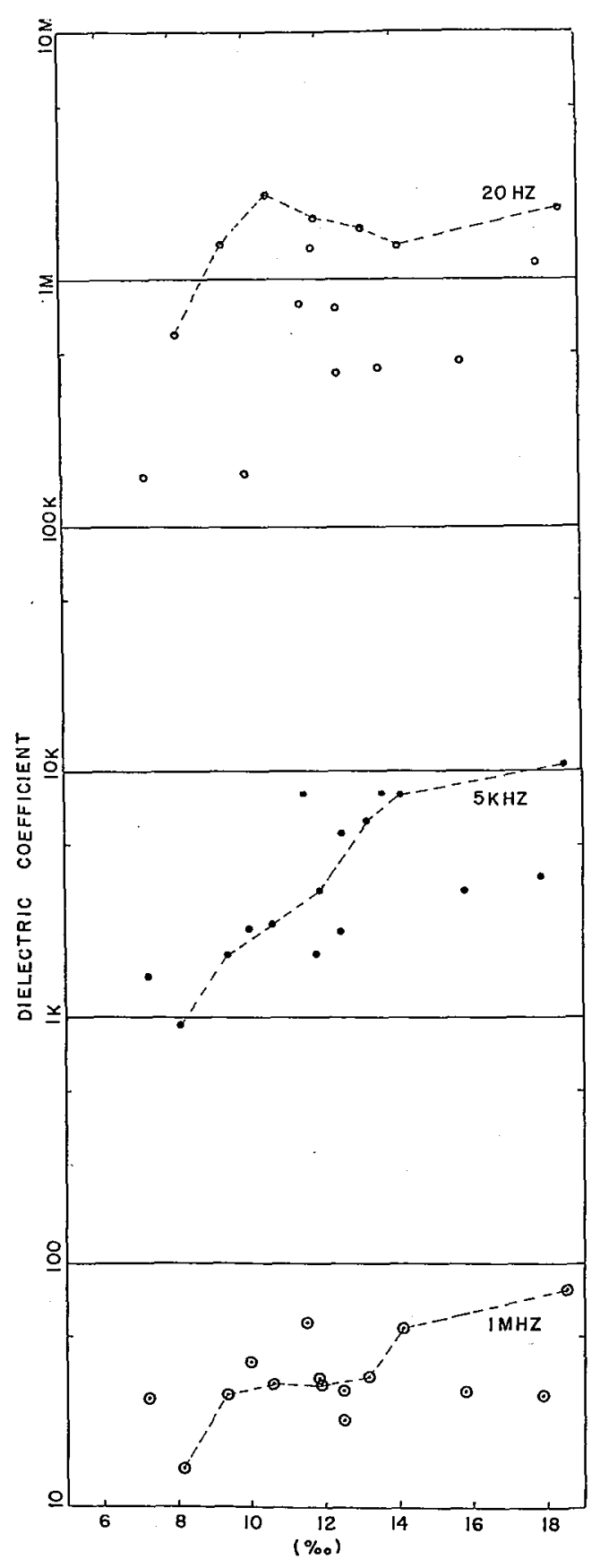

Fig. 3.

Fig. 3, 4 and 5. Electrical parameters of saline ice-salinity variation

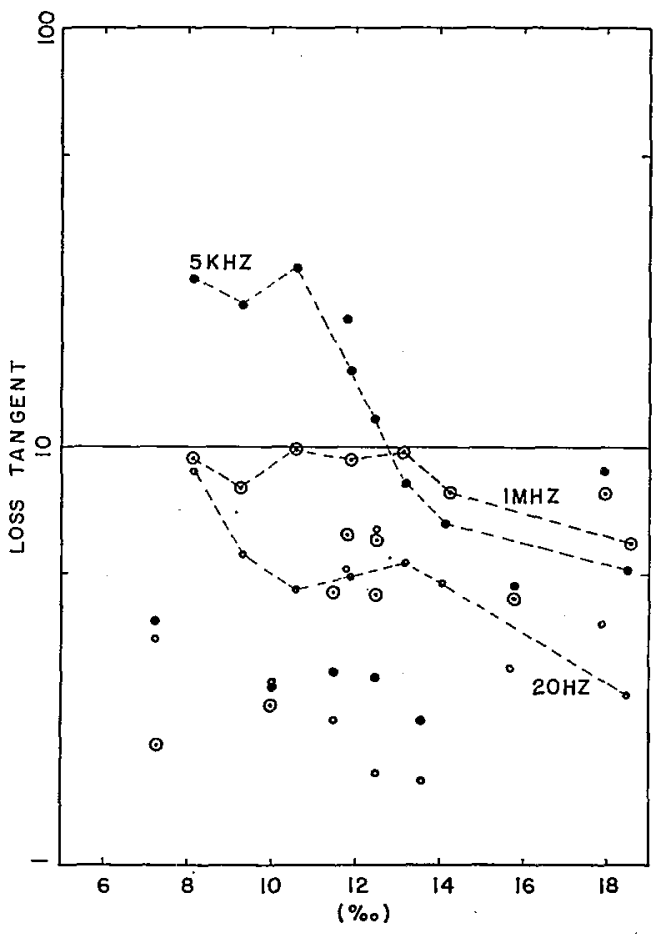

Fig. 4

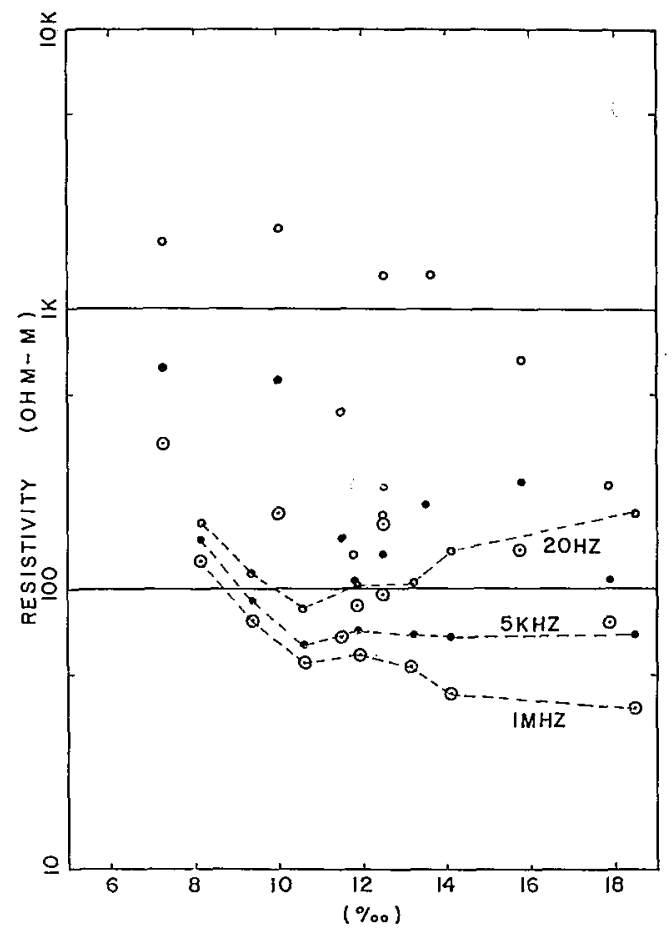

Fig. 5 

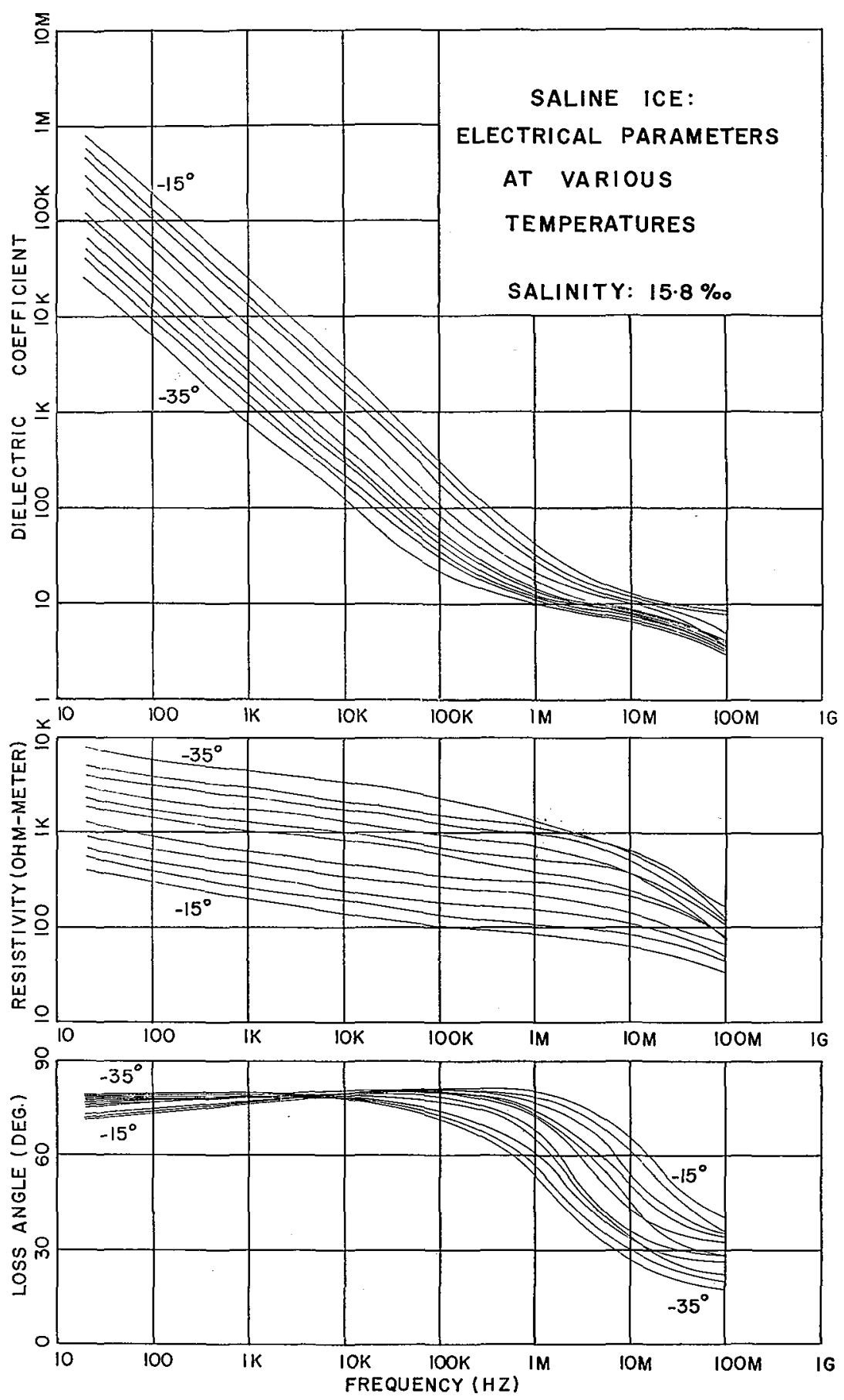

Fig. 6. Electrical parameters of șaline ice at variọus temperatures 


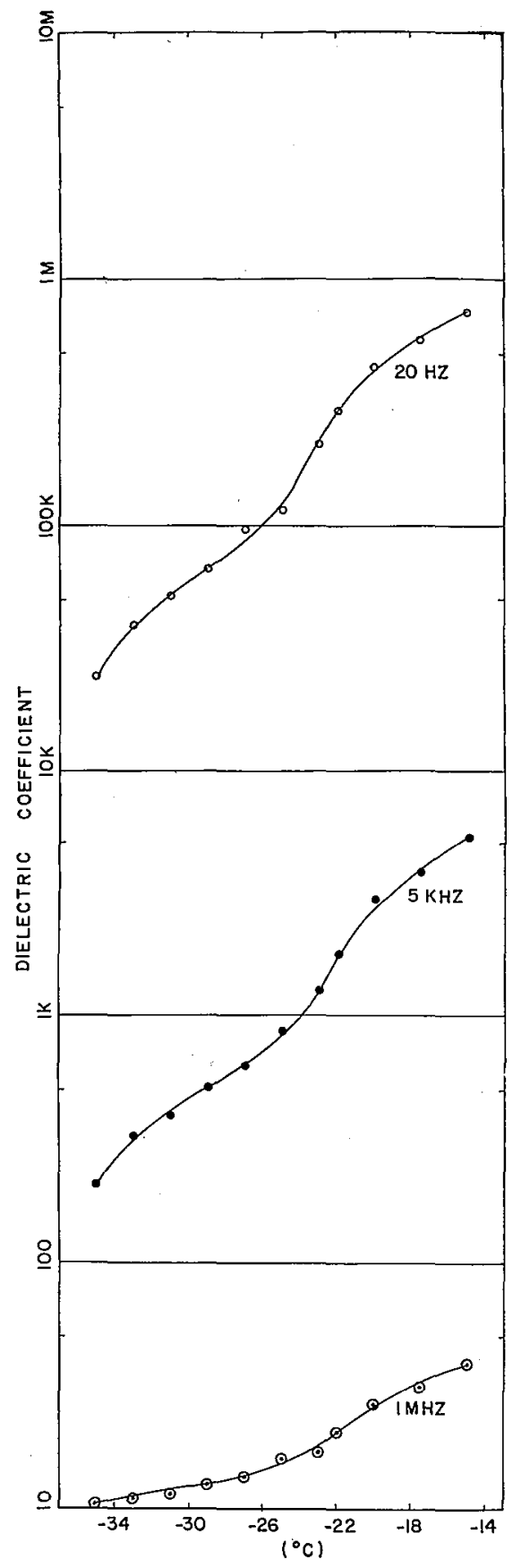

Fig. 7. Electrical parameters of saline ice-temperature variation

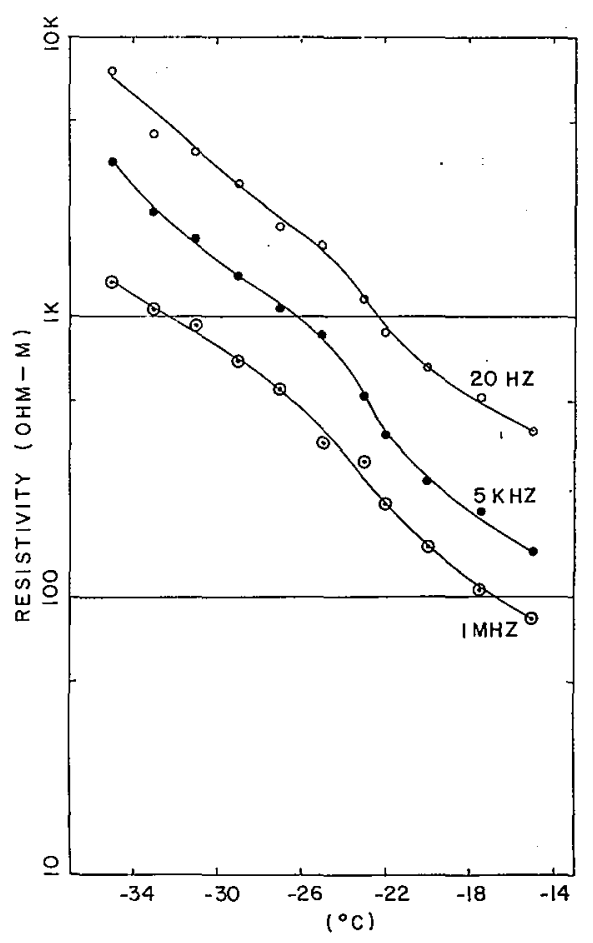

Fig. 8. Electrical parameters of saline ice-temperature variation

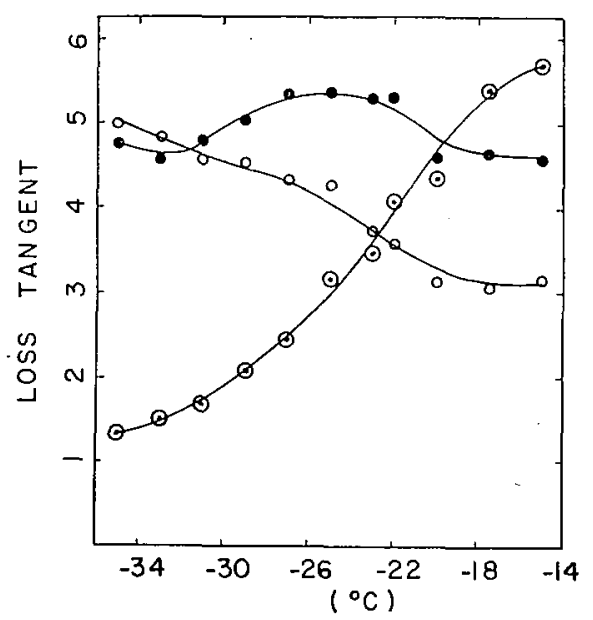

Fig. 9. Electrical parameters of saline ice-temperature variation 
values of $\rho$, and, in all cases, a rapid drop above $10 \mathrm{MHz}$ brought most curves into the range $20 \sim 60$ ohm-meters at $100 \mathrm{MHz}$ (in fair agreement with Cooks). High loss tangents, $(5 \sim 20)$ corresponding to loss angles in the range $75 \sim 85^{\circ}$, were generally observed at this temperature. The tangents usually exhibited a slight rise beyond $100 \mathrm{kHz}$, followed by a rapid drop to approximately unity by $100 \mathrm{MHz}$.

Figures 3,4 and 5 attempt to show the effect of salinity on these properties for three different frequencies, $20 \mathrm{~Hz}, 5 \mathrm{kHz}$ and $1 \mathrm{MHz}$. There is little direct correlation. The dashed lines, joining points originating from samples from one particular cell may indicate a trend (perhaps fortuitously).

The behaviour of one sample at various temperatures is shown in Fig. 6. Higher dielectric coefficients and lower resistivities are found at higher temperatures. (The temperatures of the unidentified curves may be ascertained from the abscissa of Fig. 7.) The loss tangent curves cross over each other at $10 \mathrm{kHz}$. This is illustrated in Fig. 9 . Figures 7 and 8 show clearly the changes in $\rho$ and $\varepsilon^{\prime}$ with increasing temperature. These changes are visibly most rapid near $-22.9^{\circ} \mathrm{C}$, the solid $\mathrm{NaCl} \cdot 2 \mathrm{H}_{2} \mathrm{O}$ deposition temperature.

Temperature and structure are seen to play a more important role in controlling the electrical parameters than does salinity. Also, at higher frequencies the effect of temperature is considerably less. In these points and, qualitatively, in general, our results agree with those of Wentworth and Cohn (1964).

However, for comparable salinities and temperatures our values of $\varepsilon^{\prime}$ are 2 or 3 times larger and the loss tangents greater by as much as a factor of 10 . Wentworth and Cohn observed a more definite dependence upon salinity with a possible maximum in $s^{\prime}$ and minimum in $\rho$ at 10 p.p.t. In Figs. 3 and 5 the dashed lines also show peaks or inflections at this value. It is suggested that neither set of results establishes the existence of a true effect.

A serious difference arises in their suggestion that the resistivity-temperature curves for many of their samples showed an abrupt peak near $-20^{\circ} \mathrm{C}$, with a corresponding depression in the curves for $\varepsilon^{\prime}$. Our results do not confirm this at all. It is difficult to envisage a mechanism to account for a peak of this sort.

The frequency dispersions of $\varepsilon^{\prime}$ and $\rho$ are characteristic of complex relaxation processes. When inclusions of similar sizes, shapes, and orientations, of one medium are scattered (dilutely) throughout a second medium, the two substances having different dielectric coefficients and conductivities, a somewhat Debye-like dispersion, with a single relaxation time, results (von Hippel, 1954). When the inclusions have different shapes and orientations, a spectrum of relaxation times is observed. The relaxation time spectrum of saline ice should be especially complicated by the fact that two different entities, the ions in the brine and the protons in the ice crystal, should contribute to the polarization. Some of the loss angle curves show two low maxima lying between 10 and 100 $\mathrm{kHz}$, and between $100 \mathrm{kHz}$ and $1 \mathrm{MHz}$ respectively. One is led to suspect that the latter (and the corresponding downward concavity on the $\varepsilon^{\prime}$ curve) is associated with protonic mechanisms not directly involved in the polarization of the brine inclusions. Such processes might take place at crystal imperfections, grain boundaries, crack or bubble surfaces, etc., and might be expected to show shorter relaxation times than those associated 
with the brince-cell polarization. Some success has been achieved in generating curves using two groups of relaxation times: Short times of the order of microseconds and tens of microseconds, comparing roughly with that of protons in pure ice (Jaccard, 1959) and longer times of the order of tens of milliseconds. At present, however, an explanation cannot be proposed with certainty.

It is also interesting to note that high $\left(10^{4} \sim 10^{5}\right)$ low-frequency values of $\varepsilon^{\prime}$ and comparably high loss tangents have been observed with mixed single ice crystals doped with HF (Steinemann, 1957). Sea salts do not form mixed crystals with ice, but the frequency dispersion curves reported here bear some qualitative similarity to those of the doped crystals displaced to higher frequencies.

\section{Acknowledgments}

At an earlier stage this work was supported by the Air Force Cambridge Research Laboratories, USAF, through Contract AF 19(604)-8378. Current support is being received from the Office of Naval Research, USN, Contract Nonr $4417(00)$, and the Defence Research Board of Canada, DDP Contract CP. 69-600000. We are also greatly indebted to Mr. P. Stalinski who has played a large part in these experiments, especially in the measurement programme.

\section{Additional Note}

Apparent lack of consistency among data for 15.8 p.p.t. salinity, at $-22^{\circ} \mathrm{C}$, presented on the various graphs is the result of a small but noticeable hysteresis effect occasioned by the thermal cycling. Values quoted with respect to salinity were obtained just before the cell was sectioned. Those with temperature were obtained in proper sequence during the step-wise warming from $-35^{\circ} \mathrm{C}$ and those of Fig. 2 soon after the cell had been removed from the mass.

\section{References}

1) ANDERson, D. L. 1960 The physical constants of sea ice. Research, 13, 310-322.

2) Assur, A. 1958 Composition of sea ice and its tensile strength. In Arctic Sea Ice, Nat. Acad. Sci.Nat. Res. Council U.S.A., Publ. 598, 106-138.

3) AUty, R. P. and Cole, R. H. 1952 Dielectric properties of ice and solid $\mathrm{D}_{2} \mathrm{O}$. J. Chem. Phys., 20, 1309-1314.

4) Coor, J. C. $1960 \mathrm{RF}$ properties of salty ice and frozen earth. J. Geophys. Res., 65, 1767.

5) Cummincs, W. A. 1952 The dielectric properties of ice and snow at $3.2 \mathrm{~cm}$. J. Appl. Phys., 23, 768-773.

6) Dichtel, W. J. and Lundouist, G. A. 1951 An investigation of the physical and electrical properties of sea ice. Bull. Nat. Res. Council U.S., No. 122, 122; SIPRE Document 9053 (U.S. Army).

7) DoRSEY, N. W. 1940 Properties of Ordinary Water Substance. Reinhold Publ. Co., New York, $673 \mathrm{pp}$.

8) Dougherty, T. J. 1965 Electrical properties of ice. I. J. Chem. Phys., 43, 3247-3252.

9) EDER, F. X. 1947 Das Elektrische Verhalten von Eis. Ann. Phys., 1, 381-398.

10) FröHLICH, H. 1958 Theory of Dielectrics, Oxford Clarendon Press. 178 pp. 
11) GRÄNICHER, H. et al. 1957 Dielectric relaxation and the electrical counductivity of ice crystals. Disc. Faraday Soc., 23, 50-62.

12) GRÄNICHER, H. 1963 Properties and lattice imperfections of ice crystals and the behaviour of $\mathrm{H}_{2} \mathrm{O}-\mathrm{HF}$ solid solutions. Phys. Kondens. Materie, 1, 1-12.

13). HoRigan, F. D. 1953 Electrical characteristics of snow and ice, a literature search. Quartermaster Research end Development Lab., Bibliographic Ser. 28; SIPRE Document No. $\mathrm{U} 52248$.

14) Humbel, F., Jona, F. and Scherrer, P. 1953 Anisotropie der Dielektrizitatskonstanten des Eises. Helv. Phys. Acta, 26, 17-32.

15) JACCARD, C. 1959 Etude theorique et experimentale des proprietes electriques de la glace. Helv. Phys. Acta, 32, 89-128.

16) LAMB, J. 1946 Measurements of the dielectric properties of ice. Trans. Faraday Soc, 42 , $238-244$.

17) Langleben, M. P. 1959 Some physical properties of sea ice. II. Canad. J. Phys., 37. 1438-1454.

18) MANTIS, H. T. 1951 Review of the properties of snow and ice. SIPRE Rept, 4, 1-156.

19) Perey, F. G. J. and Pounder, E. R. 1958 Crystal orientation in ice sheets. Canad. J. Phys., 36, 494-502.

20) Pounder, E. R. 1965 The Physics of Ice, Pergamon Press, Oxford, 151 pp.

21) Pounder, E. R. and Little, E. M. 1959 Some physical properties of sea ice. I. Canad. J. Phys., 37, 443-473.

22) SMith, M. and Pounder, E. R. 1960 Impurity concentration profiles in ice by an Anthrone method. Canad. J. Phys., 38, 354-368.

23) Sмүтн, C. P. and Нiтchсоск, C.S. 1932 Dipole rotation in crystalline solids. J. Amer. Chem. Soc., 54, 4631-4647.

24) Steinemann, A. 1957 Dielektriche Eigenschaften von Eiskristallen, II. Hylv. Phys. Acta, 30, 581-610.

25) Sverdrup, H. U. et al. 1942 The Oceans, Prentice-Hall, New York, 186 pp.

26) von HippeL, A. 1954 Dielectrics and Waves, John Wiley and Sons, Inc., New York, 231 pp.

27) Wentworth, F. L. and COHN, M. 1964 Electrical properties of sea ice. J. Res. Nat. Bur. Stand., 68 D, 681-691. 